\title{
Test on Durability of Shield Tunnel Concrete Segment under Coupling Multi-Factors
}

\author{
Qiang $\mathrm{Li}^{1,2}$, Hongfa $\mathrm{Yu}^{1, *}$, Haiyan $\mathrm{Ma}^{1}$, Shudong Chen ${ }^{2}$ and Shuguang Liu ${ }^{1}$ \\ ${ }^{1}$ Department of Civil Engineering, Nanjing University of Aeronautics and Astronautics, Nanjing, 210016, China; \\ ${ }^{2}$ ZheJiang College of Construction, Hangzhou, 311231, China
}

\begin{abstract}
To study the durability of shield tunnel concrete segment under coupling multi-factors, the durability and degradation law of reinforced concrete segments under the joint action of carbonation, sulfate, chloride salt and stray current was studied by accelerated environmental and direct current (DC) power simulation test. The results show that the presence of the stray current not only accelerates the migration of chloride ions to the concrete, but also makes chlorine ion gradually converge to the steel surface. The steel corrosion near the corrosion solution on the up surface of segment is more serious than the steel corrosion near the carbon dioxide on the lower surface. The interaction of chlorine ions and stray current primarily controls the durability of the segment.
\end{abstract}

Keywords: Durability of concrete, tunnel segments, stray current, chloride ion, carbonation, sulfate corrosion.

\section{INTRODUCTION}

Reinforced concrete segment is the main component of tunnel constructed by shield tunneling method. It is unique structure because it may be subjected to different environmental conditions. Compared with concrete structures in atmospheric environment, the segments may be subjected to carbonation due to the $\mathrm{CO}_{2}$ produced by car inside the tunnel, sulfate corrosion on concrete by water and soil and corrosion of chloride ion on steel. For subway tunnel, there is stray current and it may accelerate the steel corrosion. The concrete segment often works under the coupling effects of atmospheric carbonation, groundwater corrosion, stray current corrosion and loads. The degradation process is often a result of coupling damage and deterioration. The durability of shield tunnel is complex and serious [1,2].

A great deal of research has been done worldwide concerning the durability of concrete structures. Great achievements have been obtained concerning the single factor effected degradation, including the subway stray current, sulfate attack, chloride ion diffusion, carbonization, etc [3-6]. Research works on the durability and damage mechanism of concrete under the coupling effects also have been widely reported. Wu Xiong [7] studied the effects of stray current and chloride ion on mechanical properties of concrete. Zhang Ermeng $\left[8^{]}\right.$tested anti-erosion performance of metro concrete under the effect of bending load and stray current coupled with corrosive medium. Geng Jian [9] studied the degradation mechanisms of reinforced concrete in stray currents and chloride ion coexisted corrosion environment. Du Yingji [10] and Huang Wenxin [11] studied the anti erosion performance of metro engineering concrete under influence of multiple factors. Wu Zhenzhi [12] studied the migration of chloride ion of river crossing shield tunnel under soil. Zhou Xiaojun [13] studied the effect of stray current on corrosion of rebar in concrete. The majority of the previous work, however, has been focused on small specimens in a material respect. The performance of materials is somewhat different from that of component member they consists [14, 15]. Therefore, the durability results of small specimens of tunnel segment under many single factor or multiple factors only have relative or laboratory significance, which cannot truly reflect the evolution and durability of actual concrete structure in the process of service. To better understand the behavior of the segments under real environment in a structure respect, some simulated tests have conducted over the past several decades. T. Kasper [16] investigated the stability of immersed tunnel in offshore conditions under deep water wave impact. Mingfeng Lei [17] studied the durability of shield segments under coupling effect of load and chloride environment. Zhang Zhiqiang [18] evaluated the strength of corroded tunnel lining using the accelerated electrochemical corrosion technique. For given circumstances, the segments of lining structure of a tunnel may suffer attacks from mechanical, physical, and chemical even stray current actions. However, to the best of author's knowledge, little work has been done on the durability of shield tunnel concrete segment under coupling effects of carbonation, chloride, sulfate and stray current corrosion.

Therefore, aiming to investigate the durability of shield tunnel concrete segment under coupling effects, the material properties and corrosion mechanism including the depth of carbonation, chloride ion concentration distribution, the sulfate corrosion damage layer thickness, degree of reinforcement corrosion, cracking along rebar of segment under carbonization, solution attack and stray current corrosion were studied by model test using the accelerated corrosion method. Interaction and deterioration mechanism between 
Table 1. Test program.

\begin{tabular}{|c|c|c|c|c|}
\hline No. & Proportion & Corrosion solution & Corrosion time & Carbonization time \\
\hline \hline GPA-0 & A & & 18 days & 28 days \\
\hline GPA-3.5 & A & $3.5 \% \mathrm{NaCl}$ & 18 days & 28 days \\
\hline GPA-3.5-5 & A & $3.5 \% \mathrm{NaCl}+5 \% \mathrm{Na}_{2} \mathrm{SO}_{4}$ & & 28 days \\
\hline GPB-0 & B & & 18 days & 28 days \\
\hline GPB-3.5 & B & $3.5 \% \mathrm{NaCl}$ & 18 days & $2.5 \% \mathrm{NaCl}+5 \% \mathrm{Na}_{2} \mathrm{SO}_{4}$ \\
\hline GPB-3.5-5 & B & & & 2 \\
\hline
\end{tabular}

Table 2. Mix proportions.

\begin{tabular}{|c|c|c|c|c|c|c|c|c|c|c|}
\hline \multirow[b]{2}{*}{ No. } & \multirow{2}{*}{$\begin{array}{c}\text { Water } \\
\text {-to-binder } \\
\text { ratio }\end{array}$} & \multicolumn{9}{|c|}{ Mix proportions $(\mathrm{kg} \cdot \mathrm{m}-3)$} \\
\hline & & Cement & Fly ash & Slag & $\begin{array}{l}\text { Silica } \\
\text { fume }\end{array}$ & Sand & $\begin{array}{c}\text { Coarse } \\
\text { aggregate }\end{array}$ & $\begin{array}{c}\text { Water reducing } \\
\text { agent }\end{array}$ & Water & $\begin{array}{l}\text { Strength } \\
\text { N/mm2 }\end{array}$ \\
\hline A & 0.33 & 440(PII52.5) & 65 & 0 & 0 & 597.83 & 1163 & 6.56 & 164 & 70.89 \\
\hline B & 0.28 & 241(PII42.5) & 214 & 54 & 27 & 727 & 1137 & 13.4 & 150 & 58.58 \\
\hline
\end{tabular}

carbonation, chloride corrosion and stray current were analyzed. The test results provide basis for design and maintenance of the reinforced component and structure.

\section{MATERIALS AND METHODOLOGY}

\subsection{Materials}

A summary of the test program is shown in Table 1. Totally 6 segments were casted in two groups with the different mixing proportion. Each group includes 3 segments, one is controlling specimen, and the other two were soaked separately in the solution of $3.5 \% \mathrm{NaCl}$ and $3.5 \% \mathrm{NaCl}+3.5 \%$ $\mathrm{Na}_{2} \mathrm{SO}_{4}$.

The materials used in this test were locally sourced and they satisfy the requirements of respective Chinese Standards. Maximum aggregate size of the concrete was $12 \mathrm{~mm}$. The concrete was mixed following the procedures recommended by JGJ55-2000, China. Table 2 shows the mixing proportions of specimens.

The dimension of segments and arrangement of reinforcement are shown in Fig. (1). Hot-rolled Plain Steel Bar with diameter of $6.5 \mathrm{~mm}$ was used in specimens. The measured yield and tensile strength of reinforcement are $472.52 \mathrm{MPa}$ and $586.58 \mathrm{MPa}$ respectively; the designed thickness of concrete cover is $1.5 \mathrm{~cm}$, actual concrete cover is close to the $2 \mathrm{~cm}$. Radius of segment is $670 \mathrm{~mm}$, radian is $72^{\circ}$.

\subsection{Test Methodology}

For concrete shield tunnel segment in the actual work environment, its outer surface may suffer the corrosion of chloride ions and sulfate ions, inner surface may suffer the ero- sion of atmosphere and automobile exhaust. For subway tunnel, it also may be affected by the stray current damage. Because both the outer and inner surface of segment is curved, it is difficult to soak one side of segment in solution while the other side in the air. On the other hand the segment is so large that it is difficult to be accommodated in carbide box or artificial environment box. Therefore a two step method was established to test the coupling effects of ion corrosion, carbonation and stray current on durability of shield tunnel concrete segment. First step is to simulate the coupling effects of corrosive solution and stray current. The second step is to simulate the carbonization at inner part of the segment.

\subsubsection{Simulation Method of Solution and Stray Current Corrosion}

Fig. (2) shows the test device of shield segment under the combined effect of the corrosion solution and stray current. Series connection was adopted to ensure equal current flowing through the segment. Environmental relative humidity is $70 \% \pm 5 \%$, temperature $20^{\circ} \mathrm{C} \pm 5^{\circ} \mathrm{C}$, current $1 \mathrm{~A}$. Stirrups and reinforcement is not insulated which is identical with the actual engineering

A pool was made on the external surface of segment to fill the corrosion solution simulating the soil or water environment containing the $\mathrm{NaCl}$ and $\mathrm{Na}_{2} \mathrm{SO}_{4}$. Reinforcement in segment as anode and stainless steel tube placed in corrosion pool as anode were connected to DC power supply to simulate the stray current. In this way, the coupling effect of sulfate corrosion, chloride ion diffusion and stray current was simulated. 


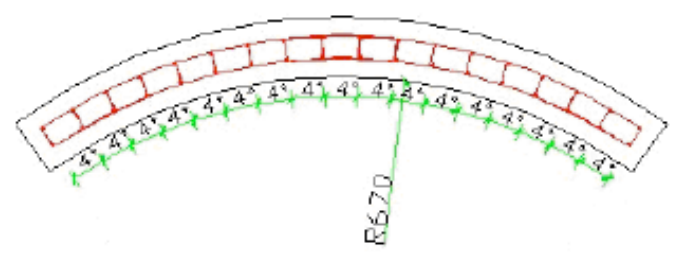

Transverse cross-sectional view

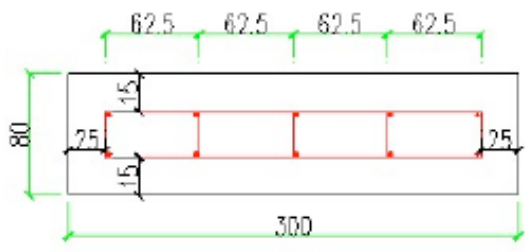

longitudinal cross-sectional view

Fig. (1). Segment model layout and reinforcement arrangement.
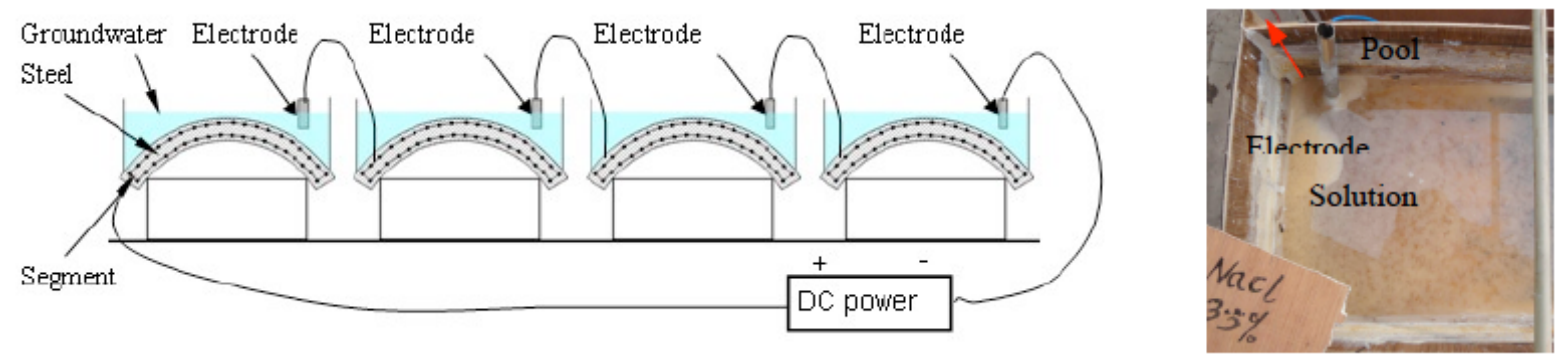

Fig. (2). Test device of shield segment under the combined effect of the corrosion solution and stray current.
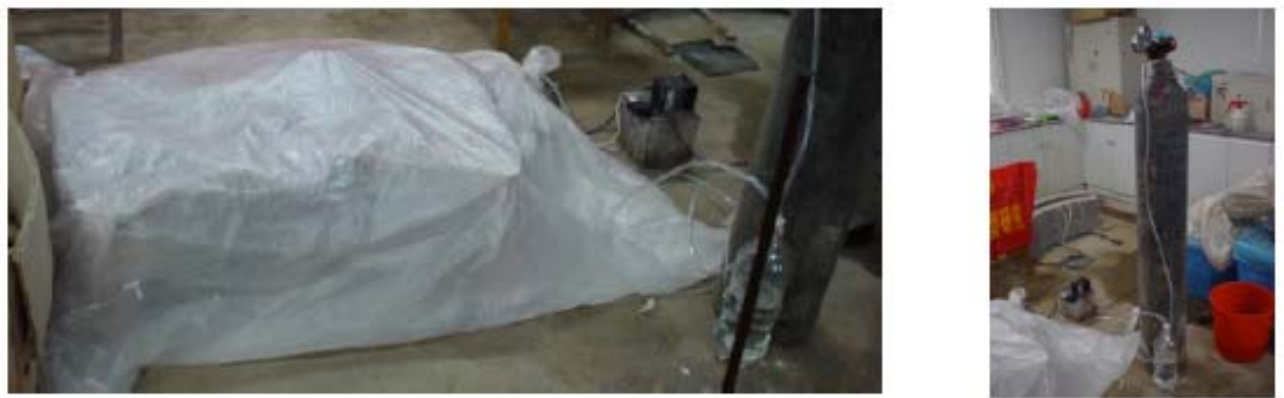

Fig. (3). Photo of carbonation test device.

\subsubsection{Simulation of Carbonization}

Fig. (3) is a photograph of carbonization test device. The carbonization corrosion of shield segment is to put its lower surface into the $\mathrm{CO}_{2}$ environment with its concentration of $20 \%$, temperature $20{ }^{\circ} \mathrm{C}$, and humidity $70 \% \pm 5 \%$. Usually carbonization box was used in carbonation test. However, due to the larger size of the segment and requirement of only inner surface of segment being carbonated, following measures were taken to meet the above requirements:

(1) To isolate the invasion of gas to the outer side of the segment, $0.3 \mathrm{~mm}$ thick plastic film with the same size of segment was covered on it. The film was sealed on the segment around four edges with sealant to ensure only the inner part of the segment be carbonated.

(2) The segment was sealed into a big plastic bag. To ensure the gas concentration, canned liquid $\mathrm{CO}_{2}$ was used in this test in which $\mathrm{CO}_{2}$ content is $20 \%$ and remaining $80 \%$ was $\mathrm{N}_{2}$. Two ventilation pipes were linked to plastic bag. To continuously make $\mathrm{CO}_{2}$ go through the bag, one end of the inlet pipe was connected to $\mathrm{CO}_{2} \mathrm{can}$, and one end of the outlet pipe was free.

(3) To control the temperature at $20^{\circ} \mathrm{C}$, a temperature and humidity controller and a dry burning bar was used. The dry burning rod was arranged in the plastic bag.
(4) To control the humidity in the $70 \%$, a humidifier and digital temperature and humidity controllers were placed in a poly bag.

\section{RESULTS}

\subsection{The Results and Analysis of Chloride Ion Erosion}

The concrete powder was collected using a drill at $5 \mathrm{~mm}$ steps to a maximum depth of $50 \mathrm{~mm}$. selective electrode method was used for determination of free chloride ion in concrete. Fig. (4) shows distributions of the chloride ion concentration. It can be seen from the Fig. (4) that the depth of chloride ion penetration is higher than the thickness of concrete cover. The concentration of chloride ion distribution curve with depth showed parabola distribution, increased at first and then decreased. The highest value is concentrated in the $20 \mathrm{~mm}$ from the surface where the reinforcement is located. Stray current would not only accelerate the migration of chloride, but also change the migration direction and distribution of chloride ion in concrete. In fact, penetration of chloride ions in concrete under the action of stray current not only shows parabola distribution in the depth direction, penetration perpendicular to the reinforcing steel bar is also shows parabola distribution. The presence of stray current causes the chloride ions to gradually gather to 
the surface of steel bar, resulting in the concentration of chloride ion in concrete at the same penetration depth is different in different regions. Chloride ions perpendicular to reinforcement surface is relatively higher.

It also can be seen from the Fig. (4) that for the same mixture, chloride ion concentration is relatively larger for $\mathrm{Cl}^{-}$ ion corroded segment compared with the $\mathrm{SO}_{4}{ }^{--}+\mathrm{Cl}^{-}$corroded segment. This is because the pore of concrete may be filled by ettringite produced by reaction of $\mathrm{SO}_{4}{ }^{2-}$ ion in the solution and hydration products. The transmission channel of $\mathrm{Cl}^{-}$ ions in the structure is restricted, which hinders the $\mathrm{Cl}^{-1}$ ion migration. Moreover, the chemical activity of $\mathrm{SO}_{4}{ }^{2-}$ ions is stronger than that of $\mathrm{Cl}^{-}$ion. $\mathrm{SO}_{4}{ }^{2-}$ ions will first react with $\mathrm{C}_{3} \mathrm{~A}$ producing ettringite. Therefore the opportunity for integration of $\mathrm{Cl}^{-}$ion and $\mathrm{C}_{3} \mathrm{~A}$ is decreased, and more likely to be absorbed by C-S-H, which alters the combination form of Cl- ions.

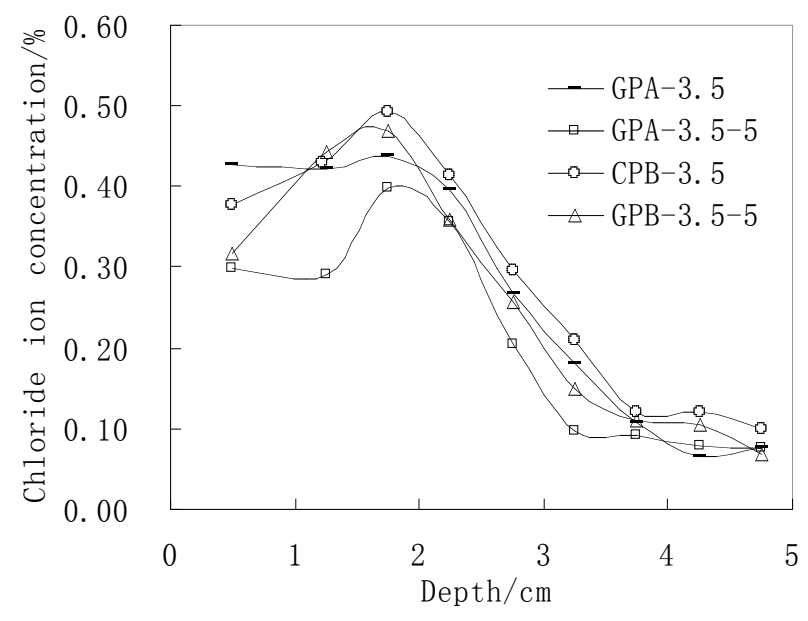

Fig. (4). Chloride ion concentration distributions.

Fig. (5) shows the EXD spectroscopy analysis of concrete in different regions for GPB-3.5-5. It can be seen from the Fig. (5) that the chloride ions were unevenly distributed in the cement paste duo to the effects of electric current. The concentration of chloride ion is increased gradually from outside to inside. The nearer the reinforcement, the higher the chlorine ion concentration is. The distribution of chloride ions of rest of 3 segments also showed the same characteristics. This further proves that the existence of stray current in addition to accelerate the migration of chloride ion in concrete, it cause the chloride ions to gradually gather to

the steel surface, increasing the concentration of chloride ion on the surface of the steel bar, and finally accelerate the corrosion of reinforcement.

\subsection{The Results and Analysis of Carbonation}

Fig. (6) shows the carbonation depth. It can be seen from the Fig. (6) that the carbonation depth of concrete segment is only 1 4 $\mathrm{mm}$. It did not exceed the thickness of concrete cover. According to the similarity theory of carbonation [19], carbonization is not a controlling factor for concrete segment compared with the chloride and sulfate ions and stray current corrosion.

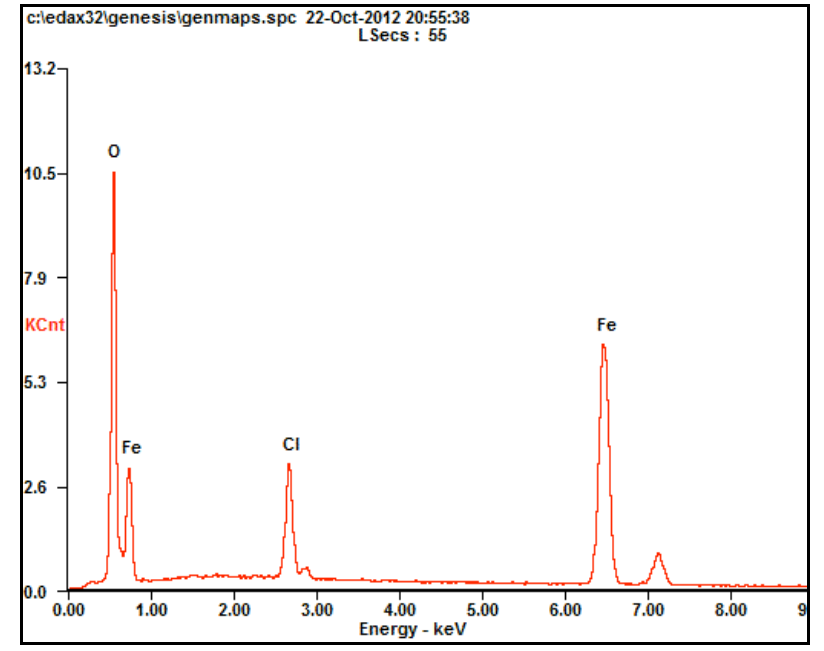

(a) Reinforced surface

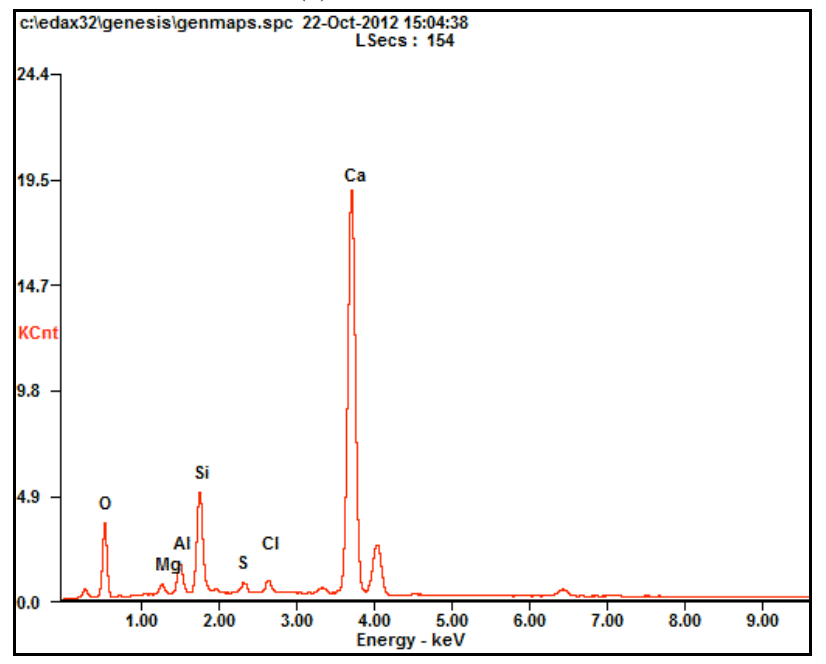

(b) $15 \mathrm{~mm}$ from the steel surface

Fig. (5). EXD spectroscopy analysis of concrete in different regions.

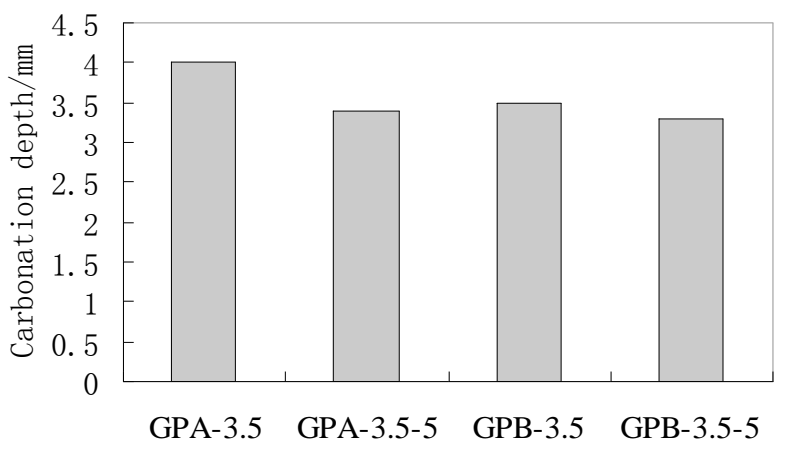

Fig. (6). Determination of carbonation depth value.

\subsection{Corrosion Damage of Segment Surface}

Fig. (7) shows the surface corrosion damage of the segment. Different degrees of cracks were appeared on the surface of segment under the coupling effect of carbonation, chloride, sulfate ion and stray current, mainly longitudinal, transverse cracks and some of corner cracks, with more or 

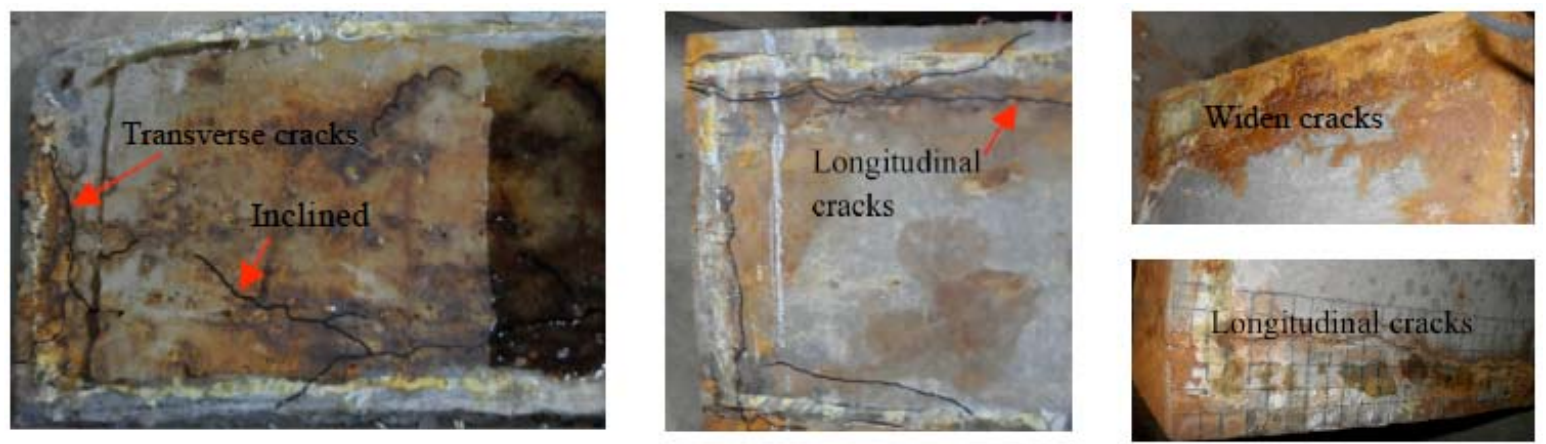

Fig. (7). Damage morphology photo of corroded segment surface.

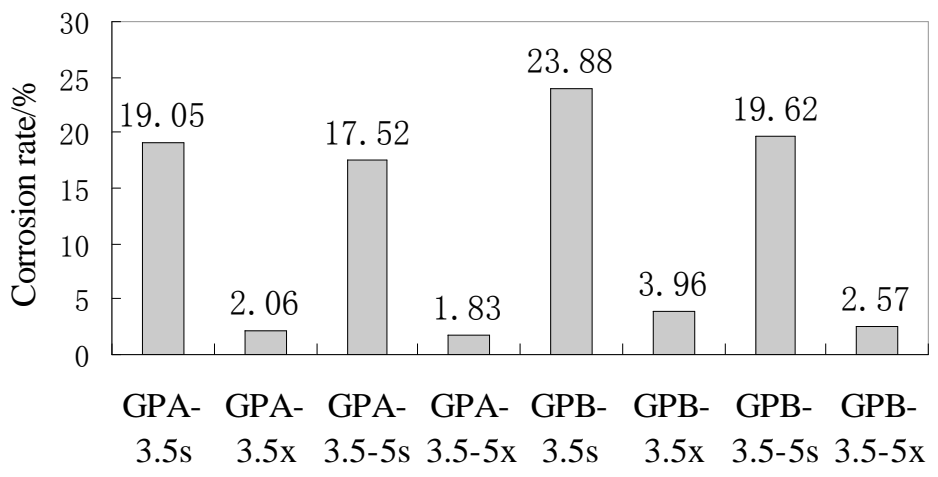

(a) The stirrups corrosion rate

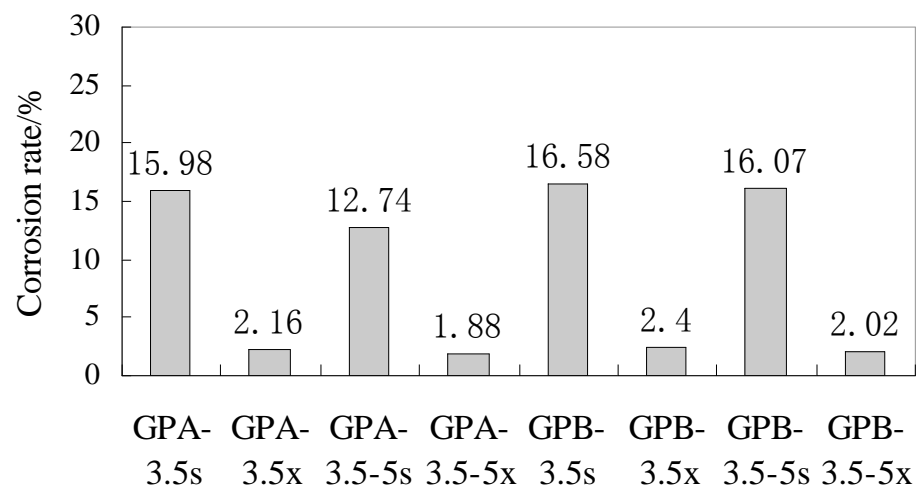

(b) Reinforcement corrosion rate

Fig. (8). Corrosion rate of reinforcement.

less inclined cracks. Crack width is ranging in $0.1 \sim 3 \mathrm{~mm}$. This is partly due to the expanded corrosion product volume causing the concrete cover to crack. This part of the cracks occurred mainly in the reinforcement position. On the other hand, the reaction of the sulfate ion and $\mathrm{Ca}(\mathrm{OH})_{2}$ in the cement producing $\mathrm{CaSO}_{4}$. $\mathrm{CaSO}_{4}$ again reacts with the hydrated calcium aluminate producing Ettringite $\left(3 \mathrm{CaO} \cdot \mathrm{A}_{2} \mathrm{O}_{3} \cdot 3 \mathrm{CaSO}_{4} \cdot 31 \mathrm{H}_{2} \mathrm{O}\right)$, whose volume was expanded 2-3 times. The coupling effect of chloride, sulfate ions and stray current caused a few widen cracks at the corner of the segment.

\subsection{Result and Analysis of Reinforcement Corrosion}

Fig. (8) shows the reinforcement corrosion rate. The results shows that the corrosion of reinforcement near the corrosion solution is more serious compared with the rein- forcement close to the inner part of the lining. Effect of stray current on inner reinforcements is much smaller than the outer ones. For same segment the corrosion of reinforcement is more serious than stirrup. This may due to the fact that the stirrup is closer to the corrosive solution. The chloride ion concentration at stirrups is greater than that at the longitudinal reinforcement. Therefore the resistivity of concrete at stirrup is smaller than that at longitudinal reinforcement. Current through the surface of the stirrup is larger. Therefore the corrosion rate is larger.

It can be seen from the Fig. (8a) that the corrosion of stirrups near the outside of the segment with the mixing proportion $\mathrm{A}$ is larger than that with the mixing proportion B. (In Fig. (8), S represents the upper reinforcement, $X$ represents the lower reinforcement). This is due to the fact that for mixing proportion $\mathrm{B}$, the mineral admixture reached $55 \%$. How- 
ever, for mixing proportion A the mineral admixture is only about $13 \%$ of the cementitious materials. The corrosion rate of reinforcement of segment in $3.5 \% \mathrm{NaCl}$ solution is larger than that in $3.5 \% \mathrm{NaCl}+5 \% \mathrm{Na} 2 \mathrm{SO}_{4}$ solution. This is because the concrete pore is filled by $\mathrm{SO}_{4}{ }^{2-}$ ion and hydration products of which hindered the migration of $\mathrm{Cl}$-ions. The resistivity of concrete increased and electrochemical equivalent of reinforcement reduced. It can be seen from the Fig. (8b) that the corrosion rate of reinforcement shows the same rules.

Fig. (9) shows the pictures of reinforcement and stirrup corrosion in segment. It can be seen from Fig. (9) that the corrosion characteristics were identical with the measured corrosion rates. Stirrup is corroded more serious at the intersection of stirrup and reinforcement. And there is obvious pitting corrosion. The reinforcement corrosion is lower than that in the none-cross area. This is mainly because of thermocouple protection [20]. The corrosion of longitudinal reinforcement at the outside is more serious, it is also because the outer longitudinal reinforcements near the corrosion solution. The corrosion of stirrups and longitudinal reinforcement in inner part of segment is significantly lighter. This shows that the local environment has great effect on corrosion of reinforcement. Using Faraday's law to predict the corrosion rate of the accelerated corrosion of steel bar may has randomness and error. It further illustrates that the performance of local materials and components can't correctly reflect the overall performance of the components, and the durability results of small specimens is difficult to reflect the evolution of durability for actual concrete structures in the process of service.

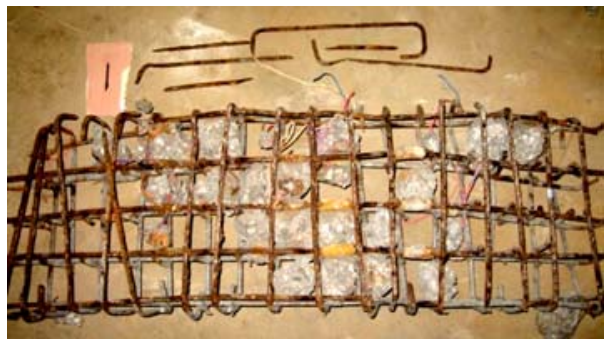

GPA-3.5

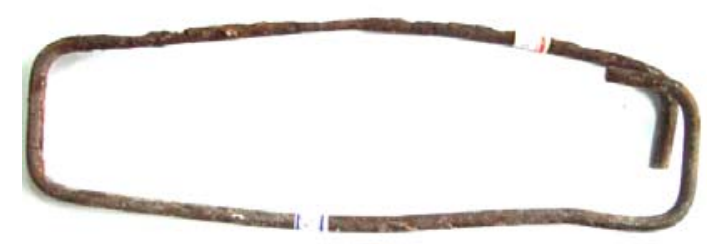

GPB-3.5

Fig. (9). Steel corrosion photos.

\section{CONCLUSION}

(1) In addition to accelerate the migration of e chloride ion in concrete, the presence of stray current also cause the chloride ions to gradually gather to the surface of steel bar. But the quantitative distribution of chloride ions in concrete under the coupling effects of chloride and stray current still need further study.
(2) The outer layer reinforcement which near the corrosion solution was corroded more seriously compared to reinforcement close to the lining of the carbon dioxide. The corrosion of stirrup is more serious than main bar for outer reinforcement.

(3) Among the various factors of carbonization, sulfate, chloride and stray current affect the durability of concrete segment, the coupling of chloride ion and stray current plays a main part.

\section{CONFLICT OF INTEREST}

The authors confirm that this article content has no conflict of interest.

\section{ACKNOWLEDGEMENTS}

Financial support from the National Basic Research Program of China (973 Program: 2015CB655100), Science and Technology Plan Projects of ZheJiang Province (2013C31011) and Science and Technology Projects of Ministry of Housing and Urban-Rural Construction of the People's Republic of China (2012-K2-13) are gratefully acknowledged.

\section{REFERENCES}

[1] Y. Yuan, Y. Bai, and J. H. Liu, “Assessment service state of tunnel structure", Tunnelling and Underground Space Technology, vol. 27, pp. 72-85, 2012.

[2] Y. Yuan, X. M. Jiang, and X. Liu, "Predictive maintenance of shield tunnels", Tunnelling and Underground Space Technology, vol. 38, pp. 69-86, 2013.

[3] S. Srikanth, and T. S. N. Sankaranarayanan, "Corrosion in a buried pressurised water pipeline", Engineering Failure Analysis, vol. 12, pp. 634-651, 2005.

[4] L. Bertolini, and M. Carsana, "Corrosion behavior of steel in concrete in the presence of stray current", Corrosion Sciences, vol. 49, no. 3, pp. 1056-1068, 2007.

[5] J. Xu, "Current Situation of Research on Durability of Concrete Structures in Subway Engineerings", Journal of Water Resources and Architectural Engineering, vol. 5, pp. 1-3, 2010.

[6] H. K. Pan, and L. D. Yang, "The durability deterioration model based on carbonation for underground concrete structures", Engineering Mechanics, vol. 7, pp. 172-178, 2008.

[7] W. Xiong, "Study on Deterioration Characteristics of Reinforced Concrete in the Presence of Stray Current and Chloride Ion", Ph. D. dissertation, Wuhan University of Technology, Wuhan, China, 2008.

[8] E. M. Zhang,"The Anti-erosion Performance of Metro Concrete under the Effect of Bending Load and Stray Current Coupled with Corrosive Medium", Ph. D. dissertation, Guangzhou, China, South China University of Technology, 2011.

[9] J. Geng, "The Research on the Deteriorated Mechanisms of Reinforced Concrete in Stray Currents and Chloride Ion Coexisted Corrosion Environment", Ph. D. dissertation, Wuhan University of Technology, Wuhan, China, 2008.

[10] Y. J. Du, "Reliability analysis of reinforced concrete structure based on durability and deterioration grade", Ph. D. dissertation, Hohai University, Nanjing, China, 2005.

[11] W. X. Huang, "Research on the Anti-Corrosion Durability of Concrete Structure of GZ Metro under Multiple Environmental Factors", Ph. D. dissertation, South China University of Technology, Guangzhou, China, 2011.

[12] Z. Z. Wu, "Study on Some Key Problem on the Durability of Shield Tunnel under River", Ph. D. dissertation, Tongji University, Shanghai, China, 2008.

[13] X. J. Zhou, and B. Gao, "Experimental Study on Metro Stray Current Corrosion of Rebars in Reinforced Concrete", Journal of the china railway society, vol. 5, pp. 99-105, 1999. 
[14] Y. H. Zhu, Y. S. Zou, "Influence of Stray Current on Chloride Ion Migrates in Concrete", Journal of Wuhan University of Technology, vol. 7, pp. 32-36, 2012.

[15] J. Geng, and Q. J. Ding, "Transport Characteristics of Chloride Ion in Concrete with Stray Current", Journal of Building Materials, vol. 1, pp. 121-124, 2010.

[16] T. Kasper, J. S. Steenfelt, L. M. Pedersen, P. G. Jackson, and R. W. M. G. Heijmans, "Stability of an immersed tunnel in offshore conditions under deep water wave impact", Coastal Engineering, vol. 55, pp.753-760, April 2008.

[17] M. F. Lei, L. M. Peng, and C. H. Shi, "An experimental study on durability of shield segments under load and chloride environ- ment coupling effect", Tunnelling and Underground Space Technology, vol. 42, pp. 15-24, May 2014.

[18] Z. Q. Zhang, and Y. A. Mansoor, "Evaluating the strength of corroded tunnel lining under limiting corrosion conditions", Tunnelling and Underground Space Technology, vol. 38, pp. 464475, September 2013.

[19] H. K. Pan, "Study on durability and reliability of underground structures based on carbonation", Ph. D. dissertation, Tongji University, Shanghai, China, 2005.

[20] M. X. Wang, "Research on Galvanic Corrosion Mechanics of Stirrups in Concrete Structure", Ph. D. dissertation, Guangxi University, GuangXi, China, 2005.

(C) Li et al.; Licensee Bentham Open.

This is an open access article licensed under the terms of the (https://creativecommons.org/licenses/by/4.0/legalcode), which permits unrestricted, noncommercial use, distribution and reproduction in any medium, provided the work is properly cited. 